\title{
Conflicto escolar y formación ciudadana. Apuntes para una lectura agonística de la cotidianidad escolar
}

Schoolarship conflict and citizenship foundation

Written notes for a agony reading of the schoolarship daily schedule

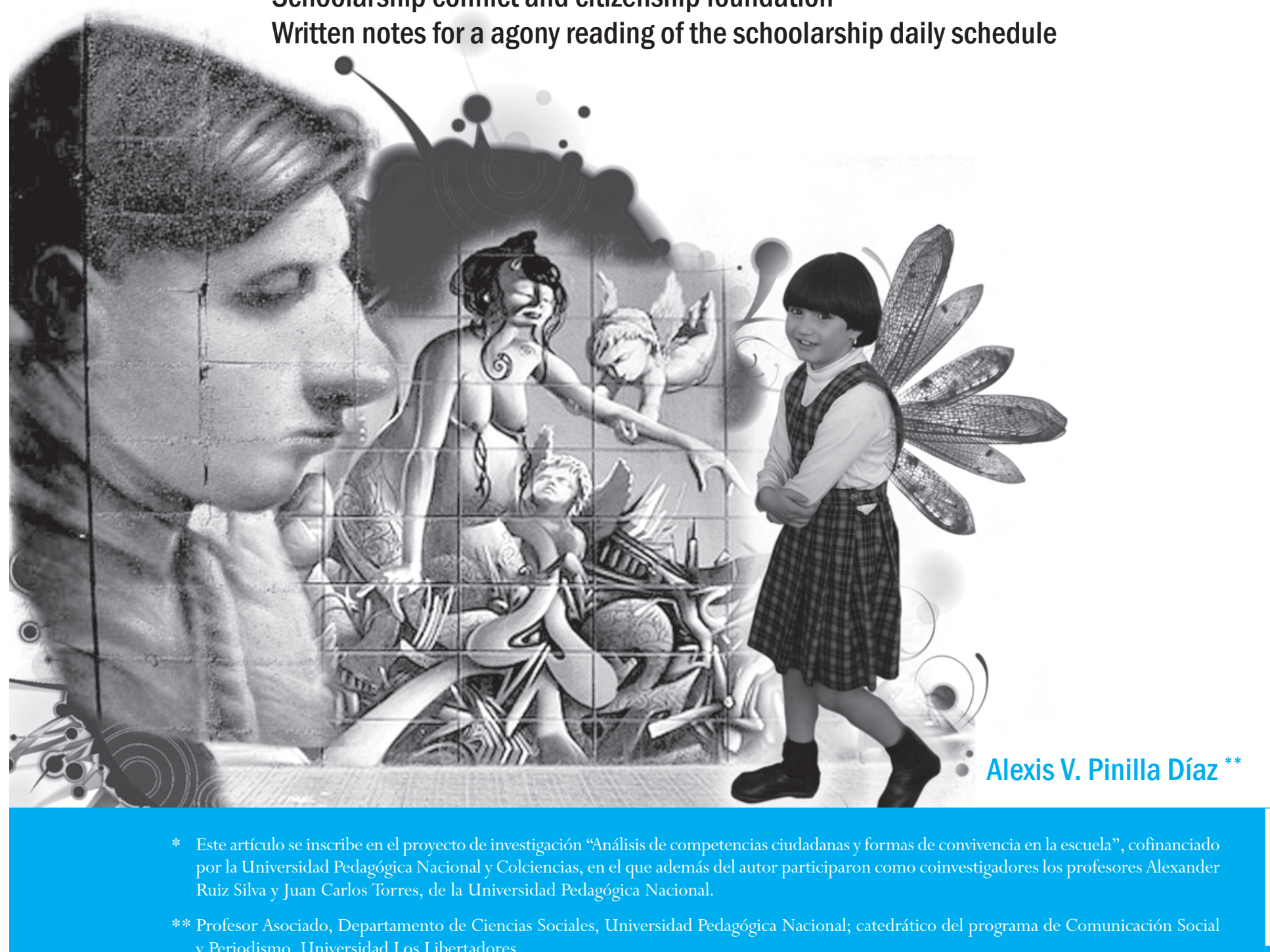


Resumen En el presente artículo se propone una reflexión sobre las características del conflicto escolar en algunas instituciones educativas de Bogotá y su relación con los procesos de formación ciudadana. El objetivo es mostrar que el conflicto no debe considerarse como algo anormal, disfuncional, en la vida escolar, sino, por el contrario, como un espacio de construcción de democracia y ciudadanía activas.

Palabras claves: conflicto, ciudadanía, democracia.

Abstract In this chapter, it's proposed a reflection about the characteristics of the school conflict in some educational institutions of Bogotá, and its relationship with the process of citycen formation. The goal is to show that the conflict in shouldn't be considered like something anormal, disfunctional in the school life, but, on the contrary, it's be considered like a space of building in democracy and active citizenships.

Keywords: conflict, citizenship, democracy. 


\section{Presentación}

Durante la última década ha sido constante la tendencia a evaluar de forma permanente a los estudiantes de educación básica y media en diferentes áreas del conocimiento. Una de ellas ha sido la relacionada con los estándares básicos de competencias ciudadanas, en los cuales la formación ciudadana se asocia estrechamente con el desarrollo moral de los niños y jóvenes

En nuestro concepto, al hacer una utilización generalizada y generalizable del desarrollo moral queda por fuera - o por lo menos se incluyen de manera tangencialaspectos específicos de la formación ciudadana, dentro de los cuales nos detendremos en el conflicto. Pareciera que la existencia de conflicto se asocia con una situación de anormalidad en la escuela, por lo cual, si las evaluaciones evidencian problemas de conflictividad, los docentes y la comunidad educativa deben proponer estrategias tendientes para su reducción.

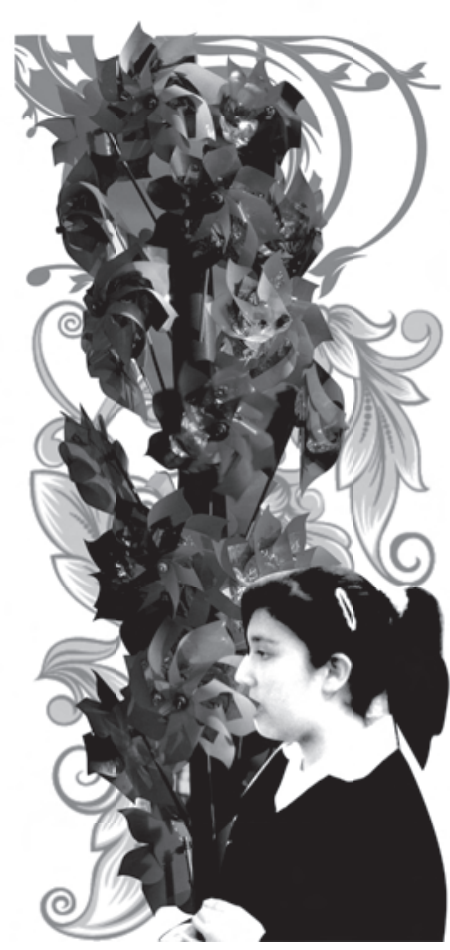




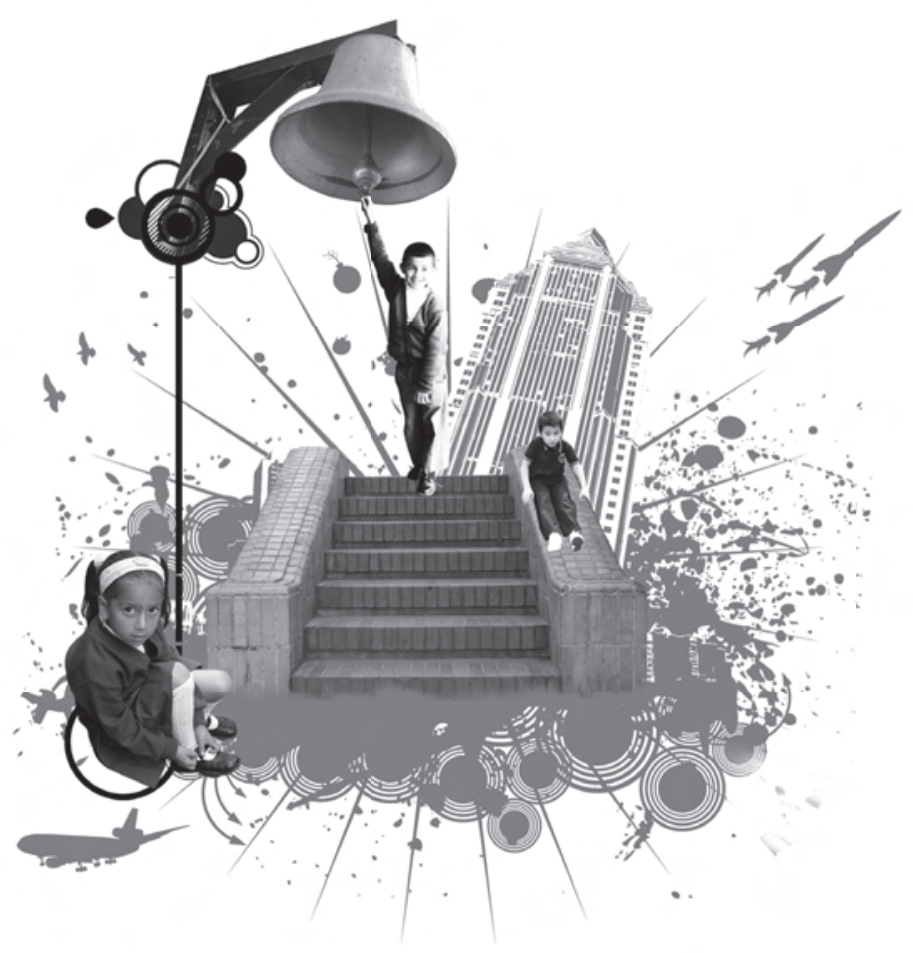

Contrario a ello, concebimos al conflicto como algo inherente a la vida en comunidad. Al pensar la escuela como un espacio sociocultural en el cual interactúan diversas visiones de mundo y en donde se ponen en juego los más variados intereses individuales y colectivos, resulta obvio reconocer que el conflicto hace parte consustancial de ella. La disputa por hegemonizar determinada versión de la realidad — bien sea de profesores, directivas, estudiantes u otros miembros de la comunidad educativa - produce, inobjetablemente, desencuentros y conflictos que, lastimosamente, se han penalizado e instrumentalizado en nuestras escuelas. Es decir, antes de concebir tales desencuentros como espacios de construcción de las subjetividades de niños y jóvenes, se organiza todo un aparato de control, sanción y corrección de las conductas consideradas desviadas. A continuación proponemos algunas reflexiones sobre el sentido del conflicto escolar en algunas instituciones

\section{El conflicto y la administración de justicia en}

\section{la escuela}

A pesar de las diferencias institucionales, en el trasfondo de los procesos de tramitación de los conflictos en los casos escogidos para este análisis subyace la siguiente ruta: diálogo con los actores directos vinculados en el conflicto (estudiantes o maestros), estudio de los casos conflictivos por parte de docentes y directivas de la institución, citación a los padres de familia y medidas de corrección (las cuales pueden ir desde llamados de atención, pasando por la firma de compromisos, hasta la expulsión del estudiante). Buena parte de este proceso se desarrolla teniendo en cuenta el historial disciplinario del alumno, consignado por los profesores en los observadores, es decir, la tramitación de los conflictos pasa, en muchos casos, por el respeto al debido proceso. 
Llama la atención, por un lado, el carácter acumulativo que cobran las medidas disciplinarias en las instituciones, ya que un número determinado de faltas leves se constituyen en una falta grave y, a su vez, la suma de varias faltas graves conlleva a una falta gravísima. Por otro lado, resulta sugestivo el reemplazo de la lógica pedagógica por la lógica jurídica para resolver los conflictos, es decir, antes que acudir a una reflexión formativa sobre el origen y las posibilidades transformadoras del conflicto, en las instituciones educativas se acude a procedimientos originarios del campo jurídico — lo cual hegemoniza una noción procedimental de los conflictos- o el recurso de acciones político-jurídicas establecidas en la Constitución de $1991^{1}$.

A pesar de esta similitud que subyace en la tramitación de los conflictos, es necesario destacar algunas particularidades de las instituciones incluidas en el estudio.
En la IED León de Greiff existe un Comité de Convivencia, conformado por un representante de los estudiantes, los maestros, padres, personal administrativo, orientadora y coordinador, al cual son enviados los casos críticos de infracción. Este comité debe garantizar el debido proceso y recomendar a la institución la aplicación del correctivo correspondiente teniendo en cuenta los siguientes parámetros:

Llamado de atención verbal con registro en el observador; citación del padre, madre o acudiente del estudiante, con registro en el observador y acta de compromiso con copia al observador; suspensión temporal cumplida fuera o dentro de la institución hasta por cinco días, con servicio prestado a la comunidad; remisión al Comité de Convivencia; reporte a Rectoría; y, por último, reporte al Consejo Directivo para el estudio de la cancelación de la matrícula (Manual de Convivencia, p. 13).

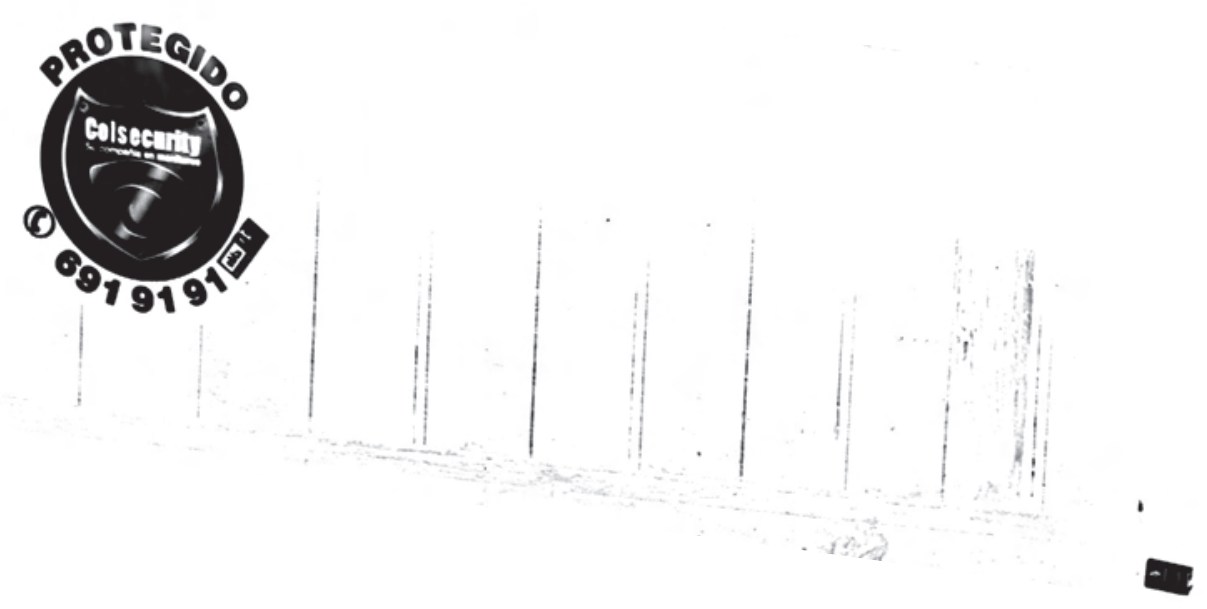

1 Herrera, Martha; Pinilla, Alexis; Infante, Raúl, “Conflicto educativo y cultura política en Colombia”, en Nómadas, $\mathrm{N}^{\circ}$ 15, Bogotá, Universidad Central, Departamento de Investigaciones, octubre de 2001. 
El proceso por el cual se administra justicia en esta institución se organiza de la siguiente forma: dos días para la constatación de pruebas, teniendo en cuenta el debido proceso; en los dos días siguientes el estudiante podrá presentar ante la coordinación su defensa; a los siguientes tres días el coordinador y el director de grupo presentarán a la rectoría un informe escrito; dentro de los cinco días hábiles siguientes la rectoría tomará la decisión de archivar el proceso si no existe motivo de cancelación de matrícula, o citar al consejo directivo para que acuerde el retiro del alumno. Si el consejo directivo toma la decisión de cancelar la matrícula, el rector deberá oficializarla mediante resolución motivada; además se podrá utilizar el recurso de reposición ante el rector y el de apelación ante el Consejo Directivo, dentro de los siguientes cinco días hábiles a la notificación.

Con base en lo anterior, queremos llamar la atención sobre el lenguaje utilizado en la institución para la resolución de los conflictos. Expresiones como "constatación de pruebas", "archivar el proceso", "recurso de apelación”, entre otras, denotan la judicialización del conflicto en la escuela, esto es, la incursión no sólo de un lenguaje sino de unas prácticas sociopolíticas propias de un campo que, como el jurídico, tiene una lógica profundamente contraria a la que funda, o debe fundar, el escenario educativo.
A pesar de estas características de la tramitación del conflicto, en esta institución tuvo lugar, de forma paralela, un proyecto de mediación escolar que obedecía a una reflexión pedagógica sobre el conflicto. Este proyecto puede incluirse dentro de los procesos de "informatización" de la justicia en la escuela, o como parte de los métodos alternativos de solución de conflictos, los cuales consideran a las propias comunidades como instancias aptas para resolver sus conflictos sin la intervención del poder judicial y en general del Estado.

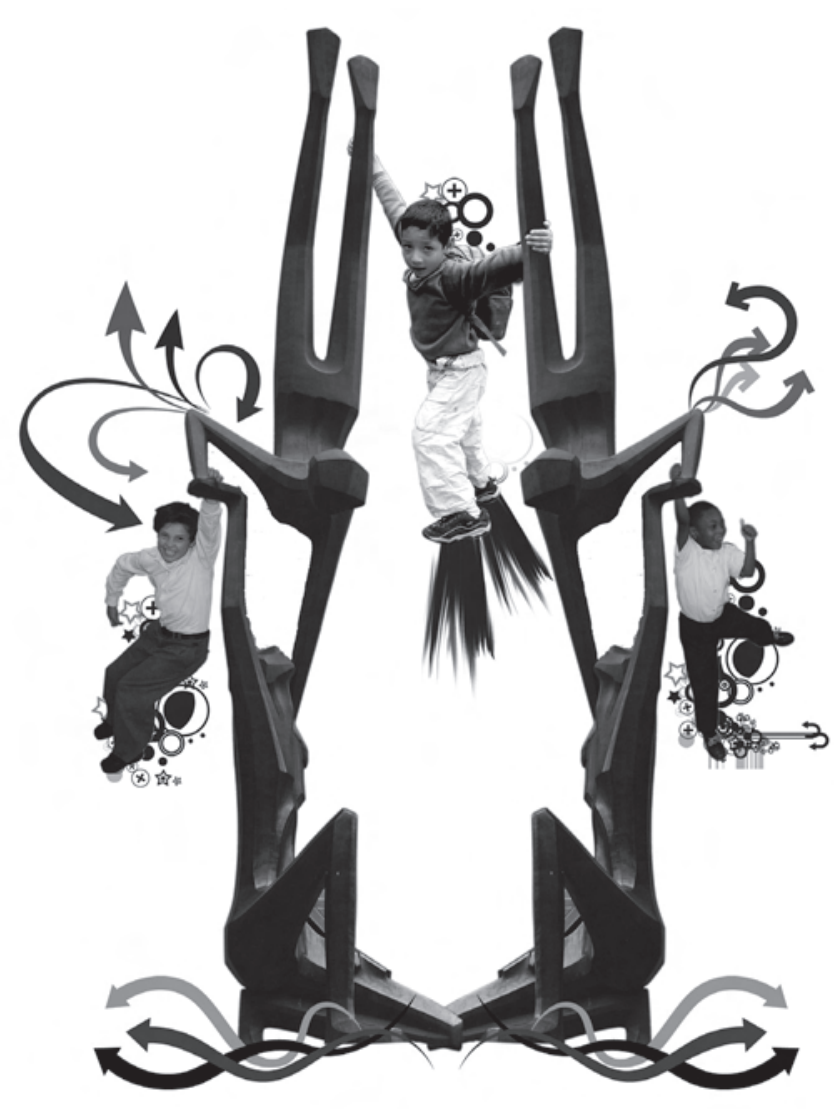


En este proyecto se parte de reconocer al conflicto como expresión de la naturaleza humana y como un hecho que puede asumirse de diversas formas, dependiendo de una serie de condiciones económicas, políticas y sociales muy particulares. Al respecto, los profesores que lideraron la reflexión sugieren que "toda vida social es conflicto, porque es cambio. No hay en la sociedad humana algo estable, porque no hay nada cierto. En el conflicto, por tanto, se halla el núcleo creador de toda sociedad y la oportunidad de la libertad, pero al mismo tiempo el reto para resolver racionalmente y controlar los problemas sociales" 2 .

Bajo esta concepción se consolidó el proyecto de mediación escolar con el objetivo de delegar en los mismos estudiantes la resolución de los conflictos. Para tal efecto se destinó un espacio físico en la institución, denominado Sala de Mediación de Conflictos, el cual fue entendido como un lugar de interacción comunicativa, pues los conflictuados llegan a ella pensando que el diálogo es una posibilidad que puede ser utilizada para resolver las diferencias y los problemas.

Paralelo a este proceso, se motivó una reflexión sobre el Manual de Convivencia con el fin de proponer un Manual de Mínimos en el que se recogieran los aspectos más generales y fundamentales de las relaciones humanas dentro del colegio, evitando que la restricción impuesta por la norma constituyera el principio básico del comportanto. En este sentido, se buscaba promover, paulatinamente, procesos de autorregulación y de plena autonomía, sin que ello significara promover la individualización. Pese a contener una propuesta innovadora y que prometía arrojar buenos frutos, «en el ambiente escolar empezó el cuestionamiento del Comité de Convivencia y del Manual de Mínimos porque estaban contribuyendo a que la disciplina en el colegio se flexibilizara demasiado y a que los estudiantes, de acuerdo con el comentario de varios padres de familia, “hicieran lo que quisieran en la institución”»"

La presión ejercida por los padres, e incluso por parte de algunos docentes del plantel, pone nuevamente en evidencia que la escuela, en su constitución histórica, ha obedecido a una lógica de disciplinamiento, lógica que ha ingresado al imaginario colectivo de los sujetos sociales (padres, maestros, incluso estudiantes) aferrándose fuertemente a la cultura política y a los procesos de socialización política que tienen lugar en la escuela. Sutilmente, cualquier intento por innovar este carácter disciplinar puede considerarse como un elemento extraño que pretender subvertir el orden natural de las cosas, por lo cual produce una serie de tensiones que alteran el orden institucional ${ }^{4}$.

2 Chaustre Avendaño, Álvaro; Cuestas Cifuentes, Marlén; Rincón, Tulia Mabel, Espacios de interacción comunicativa para la formación en cultura democrática y convivencia ciudadana, Bogotá: IDEP, 2003, p. 118.

3 Ibíd., p. 127.

4 Betancourt, José Javier; Aguilar, Juan Francisco, Dramas y tramas en el escenario escolar. La transformación innovadora de los conflictos, Bogotá: Fundación CEPECS, 2002. 
Con respecto al Colegio Mayor de San Bartolomé, existe una serie de disposiciones que delimitan el espacio de lo normal dentro de la institución. Así, el criterio de normalización, definido en el PEI, "conduce al alumno a obrar en cada momento en forma normal, es decir, actuando como se espera de él en una actividad específica, sea lúdica, religiosa, académica o social" ${ }^{5}$.

El seguimiento que se hace a los estudiantes que tienen conflicto con la normalización consiste en realizar una reunión con los padres, y después de dialogar sobre la situación, se acude a la firma de actas, compromisos o sanciones, según sea el caso, teniendo en cuenta las normas de la institución, las cuales son vistas como “expresión de voluntades libres en la convivencia social, para analizar casos particulares a la luz de los principios generales aceptados y para tener en cuenta tanto la norma como el cuidado por las personas en situaciones de conflicto; en otras palabras, para llegar a ser 'justos'
Así, "en el primer nivel, lo justo está directamente relacionado con el premio o el castigo. En el segundo nivel, lo justo se basa en criterios de igualdad y reciprocidad, lo justo se entiende como el respeto a la norma. En el tercer nivel, lo justo se refiere al reconocimiento de los derechos universales tales como el respeto a la vida o a la libertad. Para nosotros existe un cuarto nivel, en el que lo justo es el amor de servicio a los semejantes como expresión del seguimiento a la persona de Jesús"7.

Al igual que en la IED León de Greiff, para la resolución de conflictos se apela a la conciliación ${ }^{8}$, entendiendo que el conflicto puede ser una oportunidad pedagógica para mejorar las relaciones interpersonales en la institución. En ese sentido, en los documentos que orientan el desarrollo de ésta se da mayor importancia al manejo pedagógico del conflicto, que al conflicto mismo.

5 PEI, numeral 2, "Análisis de la situación institucional", p. 4.

6 Ibíd., p. 3.

7 Ibíd., p. 2.

8 En el PEI (artículos 83-87) se estipula la creación del Consejo de Conciliación, entendido como un mecanismo alternativo de acercamiento entre las partes en un conflicto. 
Como elementos comunes podemos señalar que la documentación institucional (PEI y Manual de Convivencia, principalmente) establece con claridad un sentido teleológico del conflicto en la institución, generalmente orientado a sus potencialidades pedagógicas, y propone el diálogo (mediación, conciliación) como la vía privilegiada en la solución de los conflictos, a pesar de que en la práctica, en muchas ocasiones, primen la penalización y la sanción de las conductas que desbordan lo que la institución ha definido como "normal". A continuación, haremos mención a la información encontrada en los diarios de campo y las entrevistas hechas a docentes y estudiantes de los planteles vinculados al proyecto, con el fin de cotejar los alcances de las propuestas documentales con la realidad escolar.

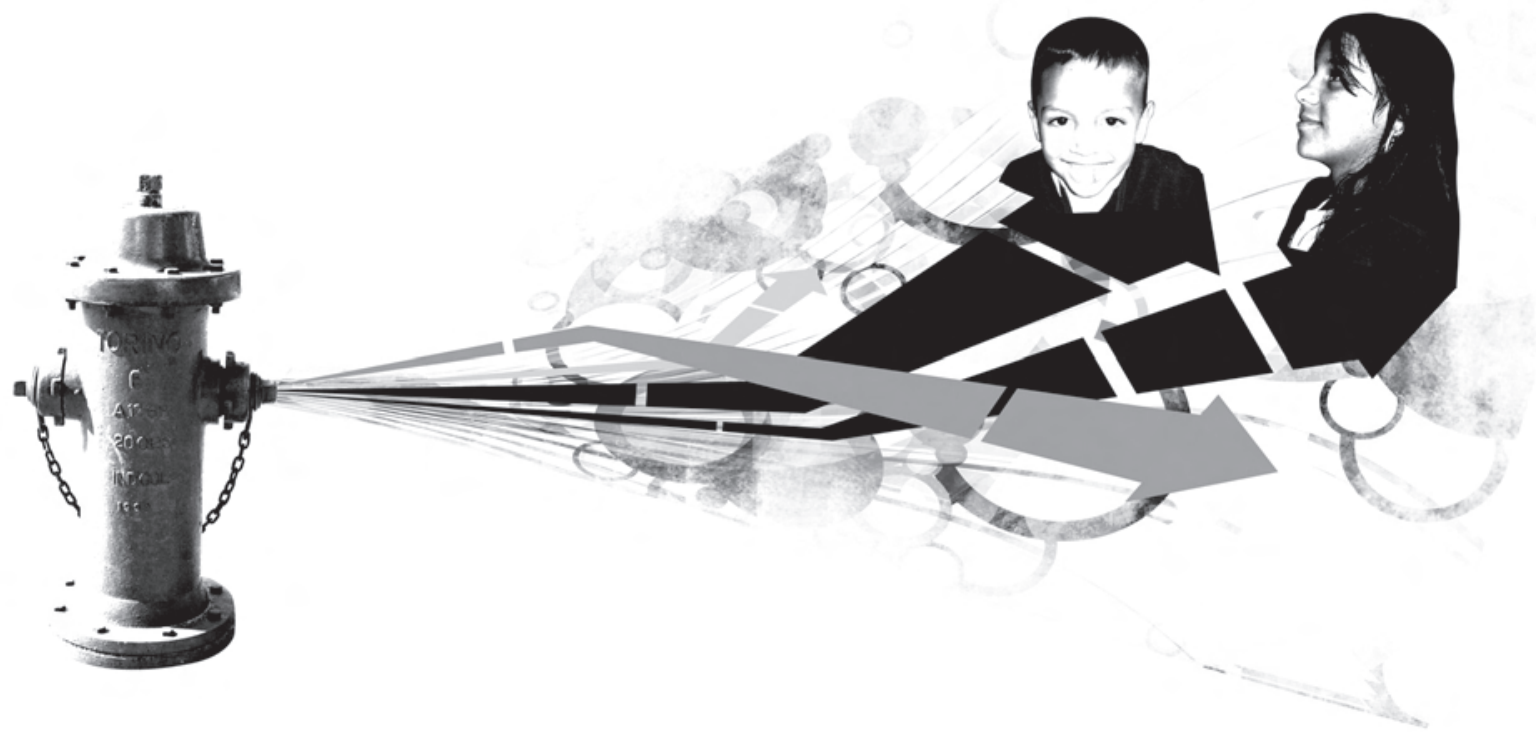




\section{Las formas del conflicto y sus vías de resolución}

En la percepción de los estudiantes sobre las formas de tramitación de los conflictos es evidente que hay un proceso de aceptación ritual de los procedimientos dispuestos por la institución educativa, es decir, a pesar de encontrar algunas contradicciones en los resultados de los procesos de conciliación de los conflictos, ellos se acoplan a los procedimientos con el fin de facilitar la vivencia diaria. Veamos algunos comentarios al respecto:

P.: ¿Cuáles son los fundamentos que tiene el colegio para tratar los conflictos?

\section{R. : Primero se trata con las persona implicadas en el conflicto; si} no se logra una solución se pasa a Coordinación, y si tampoco, a Orientación y al Comité de Convivencia, y si no, al rector, y si finalmente no tiene solución el problema, se expulsa al estudiante.

Algunos docentes perciben que el conflicto es un aspecto propio — natural — de la vida en comunidad, por lo tanto, es necesario desarrollar estrategias que permitan a los estudiantes entender la existencia de las diferencias y reconocer que es sólo a partir de ellas que es posible la vida en comunidad. En esta dirección se trata de potenciar la capacidad dialógica de los estudiantes.

P.: Cuando las cosas se les salen de las manos, ¿cómo hacen para administrar justicia?

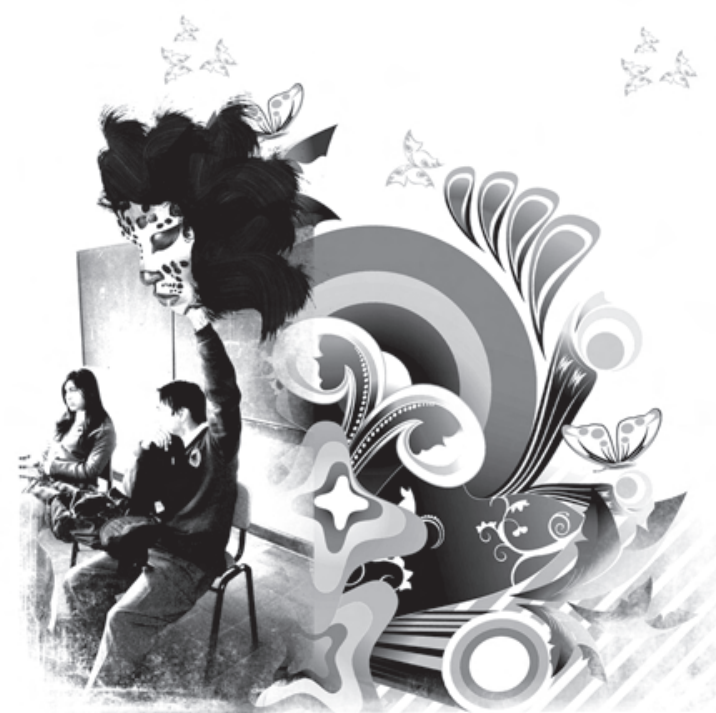

R.: Pues... cuando han ocurrido esos casos me toca conservar la calma, porque si me sulfuro, eso sólo empeora las cosas; ellos empiezan a hablar y hablar, y lo que les digo es: escriban en una hoja lo que le quieren expresar a la otra persona, como para que se desahoguen mientras lo escriben, y ahí se van dando cuenta si tenían o no razón, y además, cuando voy a leer, pues me entero de la situación; la otra persona escribe su cuento, y entro a mediar desde lo que entiendo cómo se dio el problema; mientras tanto, el calor de la situación baja. 
Sin desconocer que para algunos docentes el conflicto tiene una alta potencialidad pedagógica y formativa, consideramos que en el ambiente escolar se lo sigue percibiendo como algo anómalo y disfuncional en la vida de la institución. Parte de esta situación se explica por la limitada reflexión que se ha dado sobre el conflicto escolar, el cual, algunas veces, se ha minimizado y, otras, ha sido objeto de la prevención, más que de la reflexión ${ }^{10}$.

En términos generales, los conflictos entre los estudiantes están asociados a singularidades de la vida cotidiana, esto es, un gesto de burla, una mirada desagradable, la intromisión en asuntos personales, el abuso sobre los utensilios de clase, gustos sobre un equipo deportivo o preferencias musicales, entre otros aspectos. Sin embargo, en los cursos más avanzados $\left(9^{\circ}, 10^{\circ}\right.$ y $\left.11^{\circ}\right)$ los conflictos suelen relacionarse con problemas de pareja (celos, infidelidades, etc.) o, en menor medida, con problemas económicos.

Además de la cotidianidad, por decirlo de algún modo, de las causas del conflicto, llama la atención que los estudiantes, e incluso algunos docentes — como lo veremos más adelante-, reduzcan el conflicto a las agresiones físicas. Es decir, la primera mención a la pregunta "iqué entiende por conflicto?" se relaciona con las agresiones físicas. Valga anotar que este tipo de conflictos han trascendido el espacio de la cotidianidad masculina (en donde estaba cuasi naturalizado), pues ahora las mujeres han ganado presencia en dicho espacio. La explicación que algunos docentes dan a este aspecto es la de que la pelea se ha constituido en una estrategia de reconocimiento social por parte de las estudiantes.

En la cotidianidad de la vida estudiantil buena parte de la resolución de conflictos transita por las vías de hecho, es decir, por la agresión verbal o física, en las cuales el más fuerte impone su razón sobre los más pequeños.

\section{P.: ¿Cuál es la manera como se resuelven los conflictos} aquí en el colegio?

R. 1: A veces hablando y a veces se "agarran"; cuando no quieren hablar no hablan, y cuando se quieren agarrar pues se ponen cita o algo y lo hacen, pero cuando los profesores se dan cuenta, pues primero hablan, primero hay un diálogo.

R. 2: Hay unos chinos a los que les gusta la pelea, y esos no hablan ni nada, sino que van es peleando; en cambio hay otros que no les gusta pelear y ellos sí hablan, y si no, pues les toca irse "dando" de una vez; y hay otros que sí les gusta pelear, y a esos qué les importa hablar, se van es "dando" de una vez.

Frente a esta forma de resolver los conflictos, es necesario promover una cultura de la disputa y la confrontación de ideas como la base para llegar a acuerdos colectivos. En esta dirección, no se trata de enaltecer el discurso de la tolerancia pasiva, en el cual el sólo hecho de reconocer al otro es suficiente. No. Se trata de consolidar espacios y estrategias de tolerancia activa en donde la confrontación de las diferencias es la base de la existencia del otro. "Enseñar a vivir con conflictos significa forjar una generación de jóvenes dispuestos (as) a admitir el error, la responsabilidad, la resistencia, la reconciliación, el olvido, como forma de superar el resentimiento. Además, es el continuo aprendizaje de comprender, disputar y resolver la disputa" ${ }^{11}$.

Lo anterior facilitaría la promoción de una reflexión sobre el carácter de la democracia y la participación y el conflicto en la escuela, pues como están las cosas, pareciera que con fórmulas nuevas (Manual

10 Valderrama, Carlos, “Nociones de conflicto en actores escolares”, Nómadas, N 15, Bogotá, Universidad Central, Departamento de Investigaciones, octubre de 2001, p. 85. 
de Convivencia, Gobierno Escolar, etc.) se siguieran ocultando los mismos problemas de la organización escolar anteriores a la Constitución Política de 1991 y negando, de paso, la posibilidad de construir democracia en y desde la escuela. Para Cubides,

Desconocer la emergencia de formas distintas de agrupamiento, de interrelación social y por tanto de nuevos principios que gobiernan la acción de los sujetos individuales y colectivos, e insistir en reducir la educación y la participación política a la mera presencia en organismos formales cada vez más penetrados por el autoritarismo y la inercia propia de una cultura escolar tradicional, significa ahondar el conflicto social en la escuela e impedir la constitución de subjetividades democráticas, las cuales requieren que la institución se convierta en un espacio público en donde resulte posible la indagación crítica, el diálogo significativo de saberes y el encuentro de distintas experiencias culturales $^{12}$.

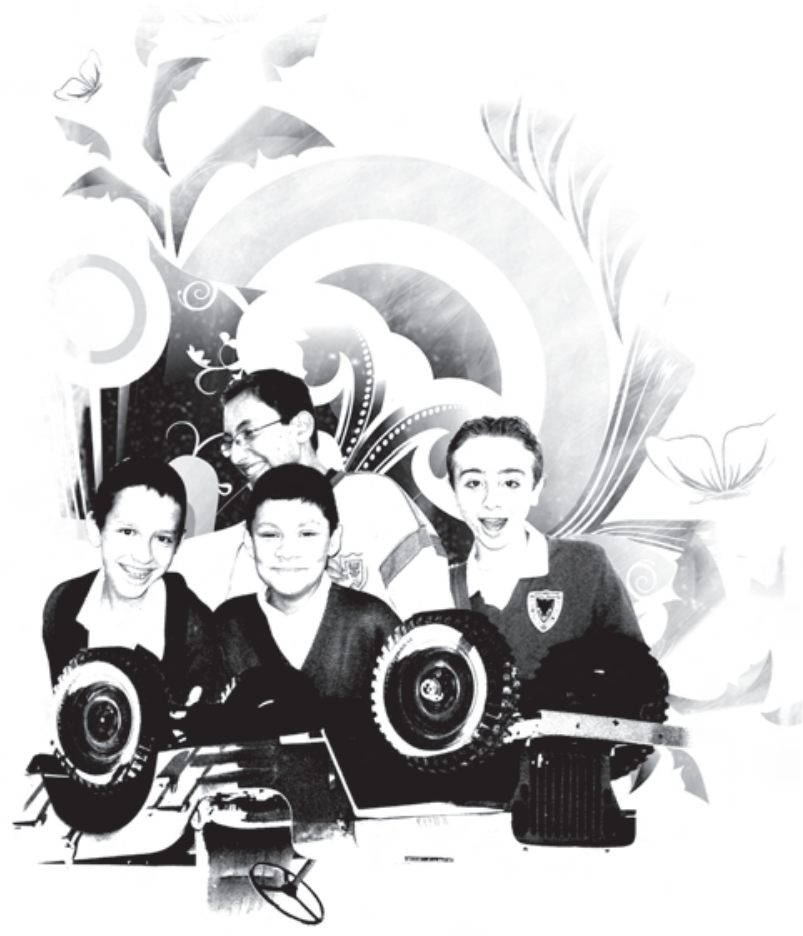

12 Cubides, Humberto, “Gobierno Escolar: cultura y conflicto político en la escuela”, en Nómadas, N 15, Bogotá: Universidad Central, Departamento de Investigaciones, 2001, p. 21 


\section{Conclusiones}

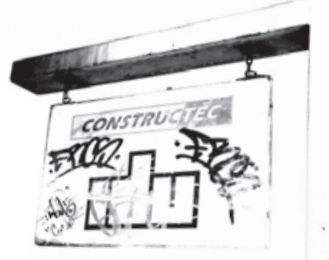

A pesar de los proyectos de innovación que se han adelantado en varias instituciones educativas y de las intenciones consignadas en leyes y decretos que propenden por la democratización del escenario escolar, hemos visto que la lógica de las instituciones educativas sigue anclada en la necesidad de corregir y disciplinar a los sujetos. En parte, esta situación se explica por los elementos que, históricamente, las han constituido: desarrollo de reglas impersonales, centralización de las decisiones, aislamiento de los diversos escenarios de participación y desarrollo de relaciones de poder paralelas y asimétricas ${ }^{13}$.

De continuarse reproduciendo estas características de la institución escolar, no sólo estaremos negando la posibilidad formativa y creadora del conflicto sino que, además, estaremos restringiendo las posibilidades de proponer y formar ciudadanías y subjetividades críticas y políticamente activas. Al no reconocer la necesidad de ampliar la participación de los niños y jóvenes en espacios de la escuela que aún siguen siendo controlados por las generaciones adultas, contribuiremos a la construcción de ciudadanías acotadas, las cuales estarán restringidas a los lugares que los adultos diseñen para el ejercicio democrático en la escuela.

En términos generales, el escenario escolar se debate entre, por lo menos, dos posiciones. Por un lado, las propuestas orientadas a que la cultura escolar se oriente por la promoción de las normas y por su enseñanza. En esta perspectiva, al definir la ciudadanía escolar se hace énfasis en el cumplimiento de la norma como condición básica para la formación ciudadana. Igualmente, los Manuales de Convivencia que se formulan en este contexto son prescriptivos o preventivos y las formas de resolución del conflicto se caracterizan por el aplazamiento y la neutralización.

En la otra mirada, la escuela debe asumirse desde la dinámica y las vivencias de los actores escolares y entendiendo el conflicto como parte central de la cotidianidad de las instituciones educativas, es decir, que éste tiene que ver con la producción de la subjetividad y su significado 
Finalmente, anotemos que el tratamiento de las tensiones cotidianas en la escuela debe darse teniendo en cuenta cada caso, ya que éstas tienen un carácter situacional y no pueden resolverse únicamente desde un Manual de Convivencia que pretende controlarlo todo, o desde los estándares básicos de competencias ciudadanas.

En conclusión, una escuela en la cual se maneje democráticamente el conflicto debe tener en cuenta aspectos básicos como el multiculturalismo, el reconocimiento de la diferencia, la participación y la descentralización del poder. Así mismo, este tipo de escuela ha de otorgarle un triple sentido a la ciudadanía: el primero, relacionado con el conflicto y su resolución (formas de convivencia); el segundo hace énfasis en la aceptación de la norma (derechos y deberes); y el último, se refiere a las capacidades comunicativas (reconocimiento de la diferencia, intersubjetividad). Entre estos tres sentidos se presentan fuertes tensiones que, de una u otra manera, impiden tener claridad sobre los avances en la formación de la ciudadanía en la escuela.

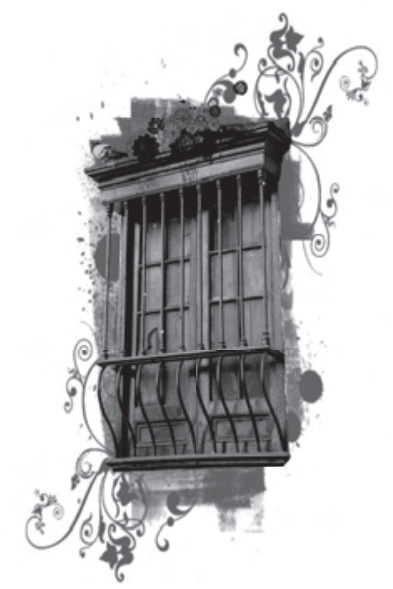



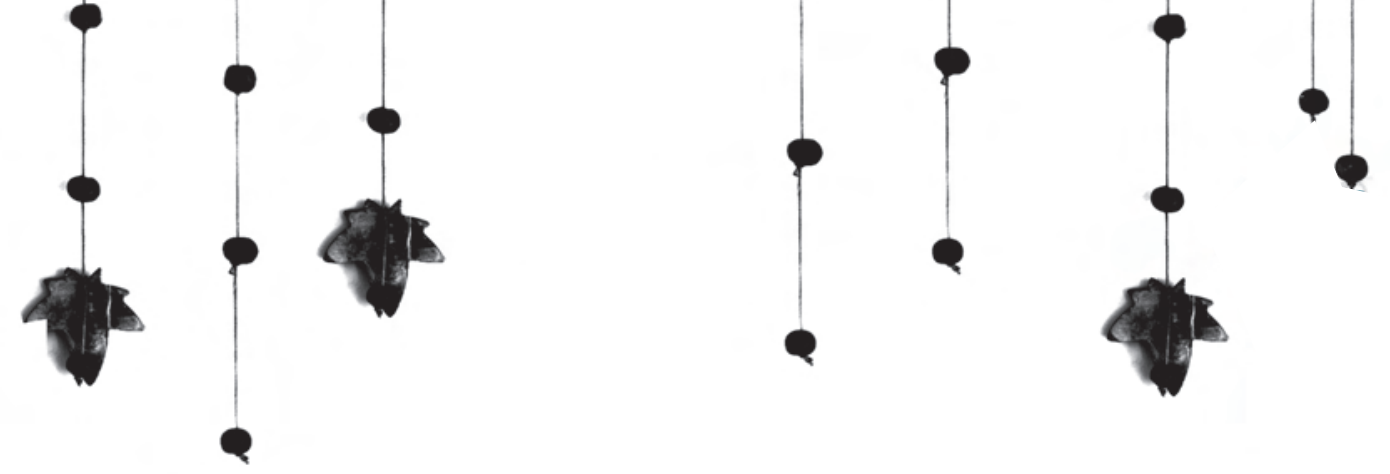

- Bibliografía

Betancourt, José Javier; Aguilar, Juan Francisco. Dramas y tramas en el escenario escolar. La transformación innovadora de los conflictos, Bogotá: Fundación Cepecs, 2002.

Borrero, Camilo. Gobierno escolar y democracia. Una experiencia de formación en derechos humanos, justicia y equidad, Bogotá: Ediciones Anthropos, 1999.

Chaustre Avendaño, Álvaro; Cuestas Cifuentes, Marlén; Rincón, Tulia Mabel. Espacios de interacción comunicativa para la formación en cultura democrática y convivencia ciudadana, Bogotá: IDEP.

Cubides, Humberto. “Gobierno Escolar: cultura y conflicto político en la escuela”, en Nómadas, N 15, Bogotá: Universidad Central, Departamento de Investigaciones, 2001.

Herrera, Martha; Pinilla, Alexis; Infante, Raúl. "Conflicto educativo y cultura política en Colombia”, en Nómadas, $\mathrm{N}^{\circ}$ 15, Bogotá: Universidad Central, Departamento de Investigaciones, 2001.

Montoya Ospina, John. Escuela, Conflicto intergeneracional y democracia, Medellín: IPC, 2003.

Valderrama, Carlos. "Nociones de conflicto en actores escolares”, en Nómadas, $N^{\circ} 15$, Bogotá: Universidad Central, Departamento de Investigaciones, 2001. 